\title{
EFFECT OF CATIONIC MICELLES OF CETYLTRIMETHYLAMMONIUM BROMIDE ON PROTONATION EQUILIBRIA OF SALICYLIC ACID DERIVATIVES
}

\author{
M. RAMANAIAH*I, S. GOUTHAM SRI', M. BALAKRISHNA' AND B. RAMA RAJU ${ }^{2}$ \\ ${ }^{1}$ Department of Chemistry, Aditya Institute of Technology and Management, Tekkali-532201, India. \\ ${ }^{2}$ School of Material Science and Engineering, Nanyang Technological University, Singapore.
}

\begin{abstract}
To gain more information about the effect of surfactant on salicylic acid derivatives, the stoichiometric protonation constants of 5-Sulphosalicylic acid and 5-Hydroxysalicylic acid in $0.0 \%-2.5 \%(\mathrm{w} / \mathrm{v})$ cetyltrimethylammonium bromide (CTAB) - water mixtures were determined at an ionic strength of $0.16 \mathrm{~mol}^{\mathrm{d}} \mathrm{dm}^{-3}$ and at $303 \mathrm{~K}$. A potentiometric method was used and the calculation of constants was carried out using the computer program MINIQUAD75. These protonation constants values have been found to shift in micellar media as compared to those in pure water. The differences in the values have been attributed to the solvent properties of the interfacial and bulk phases involving contribution from the micellar surface potential in the case of charged micelles. The trend of log values of step-wise protonation constants with mole fraction of the medium have been explained based on specific solute-solvent interactions. In this study Distributions of species, percentage of species composition, protonation equilibria and effect of influential parameters on the protonation were also discussed.
\end{abstract}

Keywords: Protonation equilibria, MINIQUAD75, Cetyltrimethylammonium bromide, 5-Sulphosalicylic acid and 5-Hydroxysalicylic acid.

\section{INTRODUCTION}

The acidity or basicity of a compound in a given medium is influenced by both the electronic effects of the substituents and the solvent effects of the medium. Moreover, it is sometimes extremely difficult to assess how much each effect contributes to the acidity or basicity. Small differences in acidity or basicity between similar molecules are also extremely difficult to interpret and one must be very careful in deciding which structural effect is the main influence on acidity or basicity

Cetyltrimethylammonium bromide (CTAB) is a cationic surfactant which tends to denature proteins and profoundly influences the bulk properties of physiological systems. They can solubilise, concentrate and compartmentalize ions and molecules ${ }^{1}$. Cationic micellar media can shift acid-base equilibria. This shift can be explained in terms of differences between the properties of the bulk solvent and of the interfacial region and perturbation of the acidbase equilibria by the electrostatic field effect of the charged interface. The dissociation equilibria of substituted benzoic acids in cationic and anionic micelles have been investigated potentiometrically². It was shown that their $\mathrm{pK}$ values shift to about 0.5-3.0 in anionic micelles. The acid-base equilibria of a number of phenols, amines and carboxylic acids in aqueous micellar solutions have been examined ${ }^{3}$.

The effect of surfactant on protonation equilibria was recognized long back $^{4}$. The apparent shift in the magnitude of protonation constants in micellar media compared to aqueous solution was attributed to the creation of a concentration gradient of protons between the interface and the bulk solution ${ }^{5}$. Further, the presence of micelles is known to alter the dielectric constant of the medium, which has a direct influence on the protonation-deprotonation equilibria $^{6-8}[27-29]$. Therefore, with this in mind, this present work is an attempt to study the impact of cationic micellar system on the protanation equilibria of the two biologically/industrially useful acids, viz., 5-Sulphosalicylic and 5-Hydroxysalicylic in the cationic micelles of CTAB.

\section{EXPERIMENTAL}

2.1 Chemicals and Standard Solutions

All the chemicals used were of analytical grade reagents. 5-Sulphosalicylic acid and 5-Hydroxysalicylic acid were obtained from the TCI, India. Solutions $\left(0.05 \mathrm{~mol} \mathrm{~L}^{-1}\right)$ of 5-Sulphosalicylic acid and 5-Hydroxysalicylic acid were prepared in triple-distilled water by maintaining $0.05 \mathrm{~mol} \mathrm{~L}^{-1}$ hydro chloric acid concentration to increase the solubility. Cetyltrimethylammonium bromide (CTAB) (Merck, India) was used as received. Hydrochloric acid (Merck, India) of $0.2 \mathrm{~mol} \mathrm{~L}^{-1}$ was prepared. The ionic strength of each solution was adjusted to $0.16 \mathrm{~mol} \mathrm{dm}^{-3}$ by addition of $\mathrm{NaCl}$. Sodium hydroxide (Merck, India) of $0.4 \mathrm{~mol} \mathrm{~L}^{-1}$ was prepared. All the solutions were standardized by standard methods. To assess the errors that might have crept into the determination of the concentrations, the data were subjected to analysis of variance of one way classification (ANOVA) ${ }^{9}$. The strengths of alkali and mineral acid were determined using the Gran plot method ${ }^{10,11}$.

\subsection{Instrumentation and Analytical Procedures}

Alkalimetric titrations were carried out in media containing varying compositions of CTAB $(0.0-2.5 \% \mathrm{w} / \mathrm{v})$ maintaining an ionic strength of 0.16 mol L ${ }^{-1}$ with sodium cholaride at $303 \pm 0.05 \mathrm{~K}$. An ELICO (Model LI-120) $\mathrm{pH}$ meter was used. Potassium hydrogen phthalate $\left(0.05 \mathrm{~mol} \mathrm{~L}^{-1}\right)$ and borax $\left(0.01 \mathrm{~mol} \mathrm{~L}^{-1}\right)$ solutions were used to calibrate the $\mathrm{pH}$ meter. In each titration, the titrand consisted of approximately $1 \mathrm{mmol}$ of hydro choleric acid. The amounts of the ligands in the titrands ranged between 0.25 and 0.50 mmols. The glass electrode was equilibrated in a well stirred CTAB-water mixture containing inert electrolyte for several days. At regular intervals titration of strong acid was titrated against alkali to check the complete equilibration of the glass electrode. The calomel electrode was refilled with CTAB-water mixture of equivalent composition as that of the titrand. The initial concentrations of reactants are given in Table 1. The details of experimental procedure and titration assembly have been detailed elsewhere ${ }^{12,13}$.

Table 1: Total initial concentrations of reactants (in mmol) in protonligand titrations

\begin{tabular}{|c|c|c|c|}
\hline \multirow[b]{2}{*}{$\begin{array}{l}\% \mathrm{w} / \mathrm{v} \\
\mathrm{CTAB}\end{array}$} & \multirow{2}{*}{$\begin{array}{l}\text { No. of } \\
\text { titration } \\
\text { curves }\end{array}$} & \multicolumn{2}{|c|}{ TL0 } \\
\hline & & $\begin{array}{l}\text { 5-Sulphosalicylic } \\
\text { acid }\end{array}$ & $\begin{array}{c}\text { 5-Hydroxysalicylic } \\
\text { acid }\end{array}$ \\
\hline 0.0 & 3 & $\begin{array}{l}0.2494 \\
0.3741 \\
0.4988\end{array}$ & $\begin{array}{l}0.2488 \\
0.3727 \\
0.4970\end{array}$ \\
\hline 0.5 & 3 & $\begin{array}{l}0.2498 \\
0.3747 \\
0.4996\end{array}$ & $\begin{array}{l}0.2493 \\
0.3740 \\
0.4987\end{array}$ \\
\hline 1.0 & 3 & $\begin{array}{l}0.2488 \\
0.3732 \\
0.4977\end{array}$ & $\begin{array}{l}0.2498 \\
0.3747 \\
0.4996\end{array}$ \\
\hline 1.5 & 3 & $\begin{array}{l}0.2515 \\
0.3773 \\
0.5031\end{array}$ & $\begin{array}{l}0.2482 \\
0.3723 \\
0.4965\end{array}$ \\
\hline 2.0 & 3 & $\begin{array}{l}0.2483 \\
0.3725 \\
0.4967\end{array}$ & $\begin{array}{l}0.2493 \\
0.3739 \\
0.4986\end{array}$ \\
\hline 2.5 & 3 & $\begin{array}{l}0.2464 \\
0.3686 \\
0.4898\end{array}$ & $\begin{array}{l}0.2482 \\
0.3723 \\
0.4965\end{array}$ \\
\hline
\end{tabular}




\subsection{Modeling Strategy}

The approximate protonation constants of 5-Sulphosalicylic acid and 5-Hydroxysalicylic acid were calculated with the computer program $\mathrm{SCPHD}^{14-16}$. The best fit chemical model for each system investigated was arrived at using non-linear least-squares computer program, MINIQUAD $75^{17}$, which exploit the advantage of constrained least-squares method in the initial refinement and reliable convergence of Marquardt algorithm. The variation of stepwise protonation constants $(\log \mathrm{K})$ with the mole fraction of the medium was analyzed on electrostatic grounds for the solute-solute and solute-solvent interactions.

\section{RESULTS AND DISCUSSION}

The best fit models containing the type of species and overall formation constants along with some of the important statistical parameters are given in Table 2. A very low standard deviation (SD) in $\log \beta$ values indicates the precision of these parameters. The small values of $U_{\text {corr }}$ (sum of squares of deviations in concentrations of ligand and hydrogen ion at all experimental points) corrected for degrees of freedom indicate that the experimental data can be represented by the model. The small values of mean, standard deviation and mean deviation for the systems corroborate that the residuals are around zero mean with little dispersion.

Table 2: Best fit chemical models of acido-basic equilibria of 5-Sulphosalicylic acid and 5-Hydroxysalicylic acid in CTAB-water mixtures. Temp= $303 \mathrm{~K}$, Ionic strength $=0.16 \mathrm{~mol} \mathrm{dm}^{-3}$.

\begin{tabular}{|c|c|c|c|c|c|c|c|c|}
\hline $\begin{array}{l}\% \mathrm{w} / \mathrm{v} . \\
\text { CTAB }\end{array}$ & $\log \beta 1(\mathrm{SD})$ & $\log \beta 2(\mathrm{SD})$ & $\mathrm{NP}$ & Ucorr & Skewness & Kurtosis & $\chi^{2}$ & $\mathrm{R}$ \\
\hline \multicolumn{9}{|c|}{ 5-Sulphosalicylic acid (pH range $1.40-11.50)$} \\
\hline 0.0 & $11.17(3)$ & $13.84(4)$ & 125 & 17.56 & 1.07 & 4.73 & 25.90 & 0.0184 \\
\hline 0.5 & $11.12(3)$ & $13.56(8)$ & 28 & 7.69 & 0.06 & 4.65 & 9.14 & 0.0283 \\
\hline 1.0 & $11.09(5)$ & $13.37(6)$ & 143 & 69.07 & 1.32 & 49.57 & 93.52 & 0.0378 \\
\hline 1.5 & $11.15(2)$ & $12.97(3)$ & 191 & 18.35 & -0.75 & 18.50 & 28.01 & 0.0146 \\
\hline 2.0 & $11.08(4)$ & $12.79(6)$ & 104 & 51.37 & 5.02 & 0.75 & 19.54 & 0.0434 \\
\hline 2.5 & $11.01(5)$ & $13.28(6)$ & 62 & 27 & 0.92 & 7.33 & 19.87 & 0.0376 \\
\hline \multicolumn{9}{|c|}{ 5-Hydroxysalicylic acid (pH range $1.60-11.50$ ) } \\
\hline 0.0 & $10.23(1)$ & $13.10(3)$ & 129 & 10.15 & -0.06 & 3.38 & 5.38 & 0.0158 \\
\hline 0.5 & $10.21(5)$ & $12.67(7)$ & 151 & 8.99 & 0.66 & 5.48 & 26.53 & 0.0440 \\
\hline 1.0 & $10.20(4)$ & $12.58(7)$ & 104 & 80.58 & 3.37 & 16.43 & 107.31 & 0.0637 \\
\hline 1.5 & $10.15(4)$ & $12.57(6)$ & 101 & 58.28 & 1.17 & 4.82 & 11.62 & 0.0528 \\
\hline 2.0 & 10.19(3) & $12.75(5)$ & 89 & 40.00 & 2.34 & 11.45 & 64.79 & 0.0453 \\
\hline 2.5 & $10.18(3)$ & $12.79(5)$ & 78 & 39.47 & 1.94 & 9.40 & 65.44 & 0.0488 \\
\hline
\end{tabular}

$\mathrm{U}_{\text {corr }}=\mathrm{U} /(\mathrm{NP}-\mathrm{m}) \mathrm{X} 10^{8} ; \mathrm{NP}=$ Number of points; $\mathrm{m}=$ number of protonation constants; $\mathrm{SD}=$ Standard deviation

The kurtosis values in the present study indicate that the residuals form leptokurtic pattern. The values of kurtosis given in Table 2 are between 49.57 and 0.75 . The values of skewness recorded in Table 2 are between -0.75 and 5.02. These data evince that the residuals form a part of normal distribution; hence, least squares method can be applied to the present data. The sufficiency of the model is further evident from the low crystallographic R-values. These statistical parameters thus show that the best fit models portray the acido-basic equilibria of 5-Sulphosalicylic acid and 5-Hydroxysalicylic acid in CTABwater mixtures. The stoichiometric protonation constants of 5-Sulphosalicylic acid and 5-Hydroxysalicylic acid determined in various CTAB-water mixtures are listed in Table 3.

Table 3: Stoichiometric Protonation constants of 5-Sulphosalicylic acid and 5-Hydroxysalicylic acid in CTAB-water mixtures. Temp= $303 \mathrm{~K}$, Ionic strength $=0.16 \mathrm{~mol} \mathrm{dm}^{-3}$.

\begin{tabular}{|c|c|c|c|c|}
\hline \multirow{2}{*}{$\%$ w/v CATB } & \multicolumn{2}{|c|}{ 5-Sulphosalicylic acid } & \multicolumn{2}{c|}{ 5-Hydroxysalicylic acid } \\
\cline { 2 - 5 } & $\log K_{I}$ & $\log K_{2}$ & $\log K_{I}$ & $\log K_{2}$ \\
\hline 0.0 & 2.66 & 11.17 & 2.86 & 10.23 \\
\hline 0.5 & 2.43 & 11.12 & 2.46 & 10.21 \\
\hline 1.0 & 2.27 & 11.09 & 2.38 & 10.20 \\
\hline 1.5 & 1.82 & 11.15 & 2.42 & 10.15 \\
\hline 2.0 & 1.71 & 11.08 & 2.56 & 10.19 \\
\hline 2.5 & 2.27 & 11.01 & 2.61 & 10.18 \\
\hline
\end{tabular}

\section{1. Secondary Formation Functions}

Secondary formation functions like average number of protons bound per mole of ligand $\mathbf{n}_{\mathrm{H}}$ and number of moles of alkali consumed per mole of ligand (a) are useful to detect the number of equilibria. Plots of $\overline{\mathbf{n}}_{\mathrm{H}}$ versus $\mathrm{pH}$ for different concentrations of the ligand should overlap if there is no formation of polymeric species. Overlapping formation curves for 5-Sulphosalicylic acid and 5-Hydroxysalicylic acid (Figure 2) rule out the polymerization of the ligand molecules. 
(A)

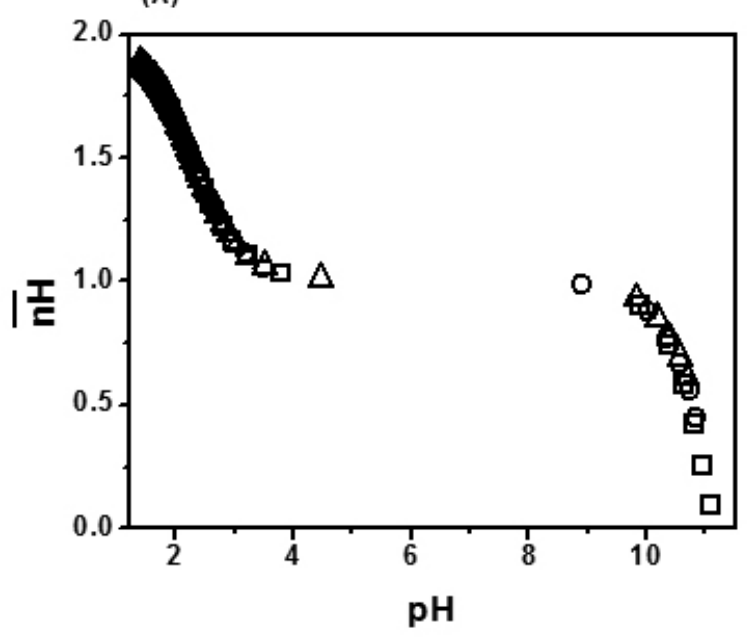

(B)

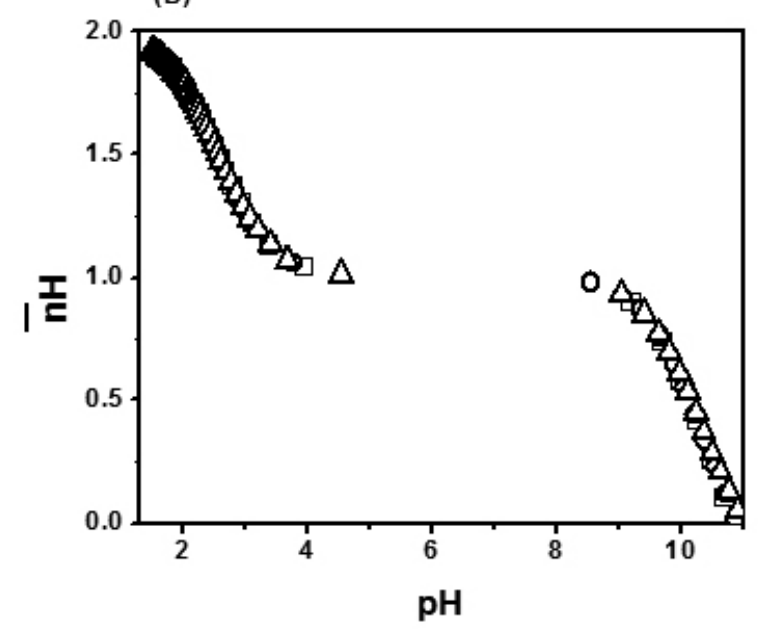

Figure 2: Plots of $\overline{\mathbf{n}}_{\mathrm{H}}$ versus pH in $2.5 \% \mathrm{w} / \mathrm{v}$ CTAB -water mixture; (A) 5-Sulphosalicylic acid (B) 5-Hydroxysalicylic acid, ( $\Delta$ ) $0.25,(\circ) 0.375$, and ( $\square) 0.50 \mathrm{mmol}$, respectively.

The $\mathrm{pH}$ values at half integral values of $\overline{\mathbf{n}}_{\mathrm{H}}$ correspond to the protonation constants of the ligands. Two half integrals (1.5 and 0.5) in the case of 5-Sulphosalicylic acid (Figure 2.A) and 5-Hydroxysalicylic acid (Figure 2.B) emphasize the presence of two protonation-deprotonation equilibria in the $\mathrm{pH}$ range of present study. The number of plateaus in the formation curves corresponds to the number of these equilibria

(A)

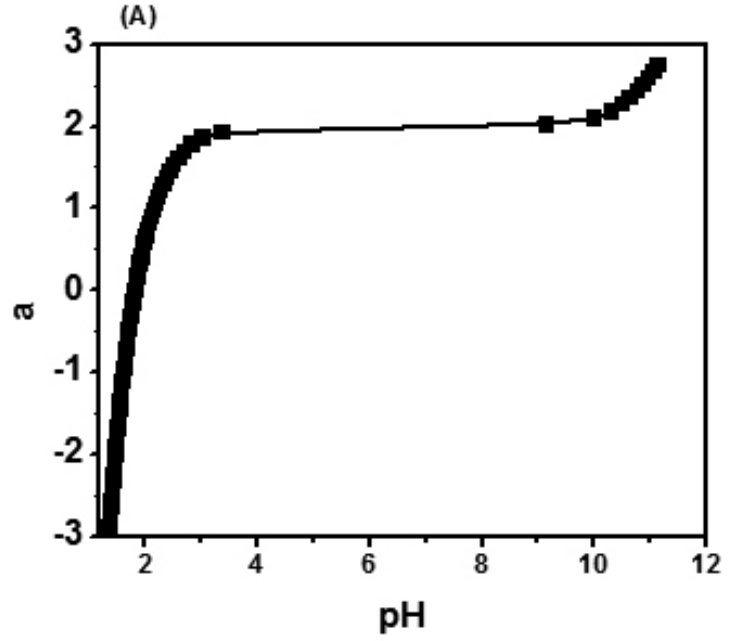

The plots of a versus $\mathrm{pH}$ are given in Figure 3. The negative values of a correspond to the number of moles of free acid present in the titrand and the number of associable protons. The positive values of a indicate the number of dissociable protons in the ligand molecules. The maximum value of a in Figure 3 is +3 , which indicates that 5 -sulphosalicylic acid and 5-hydroxysalicylic acids has three dissociable protons.

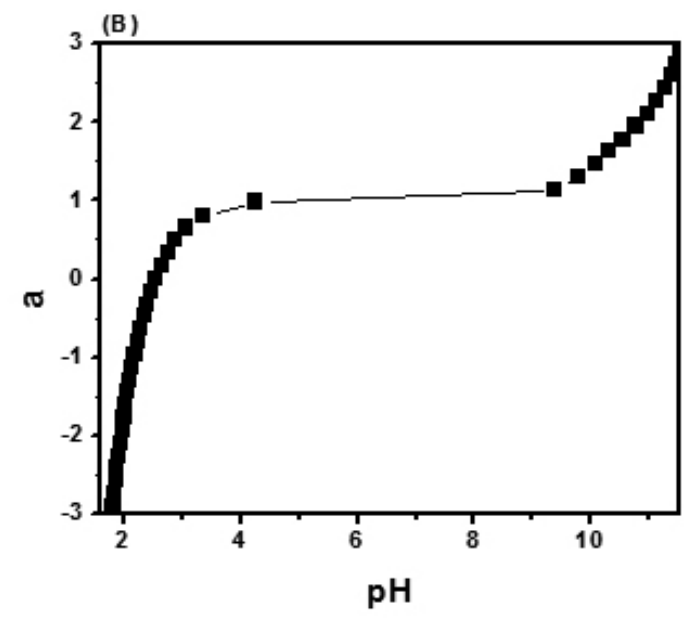

Figure 3: Variation of a with $\mathbf{p H}$ in $2.0 \% \mathrm{w} / \mathrm{v}$ CTAB -water mixture; (A) 5-Sulphosalicylic acid (B)5-Hydroxysalicylic acid, respectively.

\subsection{Distribution Diagrams}

Typical distribution plots produced by DISPLOT ${ }^{18}$ using protonation constants from the best fit models are shown in Figure 4. A single representative plot is shown for each system at a particular CTAB-water concentration. $\mathrm{LH}_{2}^{-}$ of 5-Sulphosalicylic acid is present to an extent of $98 \%$ in the $\mathrm{pH}$ range $2.0-$ 11.0. The distribution plot of 5-Sulphosalicylic acid in Figure 4(A) is shows the existence of $\mathrm{LH}_{2}^{-}, \mathrm{LH}^{2-}$ and $\mathrm{L}^{3-}$. In the case of 5-Hydroxysalicylic acid, $\mathrm{LH}_{2}^{-}$is present to an extent of $97.0 \%$ in the $\mathrm{pH}$ range 2.0-10.0. The distribution plot of 5-Hydroxysalicylic acid in Figure 4(B) shows the existence of $\mathrm{LH}_{3}, \mathrm{LH}^{-}$and $\mathrm{LH}^{2-}$. The corresponding protonation-deprotonation equilibria are shown in Figure 5.

\subsection{Effect of surfactant}

These protonation constants have been considered in some detail to gain more information about the effect of solvent composition on the corresponding equilibria. For this purpose, $\log K_{1}$ and $\log K_{2}$ values have been plotted as a function of the mole fraction of CTAB for 5-Sulphosalicylic acid and 5-Hydroxysalicylic acid. The logarithm of step-wise protanation constants of 5-Sulphosalicylic acid and 5-Hydroxysalicylic acid determined in various CTAB-water mixtures are listed in Table 3.

So Many workers were of the opinion that both electrostatic and nonelectrostatic effects should be considered even in the case of simple acidobasic equilibria; one dominates the other, depending upon the nature of solute and solvent ${ }^{19,20}$. Born's classical treatment ${ }^{21}$ holds good in accounting for the electrostatic contribution to the free energy change. The number of micelles increases with the concentration of surfactant and oppositely charged ions are concentrated in the Stern layer. According to Born's classical treatment, the energy of electrostatic interaction or the logarithm of step-wise protanation constant $(\log \mathrm{K})$ should vary linearly as a function of mole fraction of the medium. Such linear variation of the protonation constants of 5-Sulphosalicylic acid and 5-Hydroxysalicylic acid (Figure 6) in CTAB-water mixture shows the dominance of electrostatic interactions. 

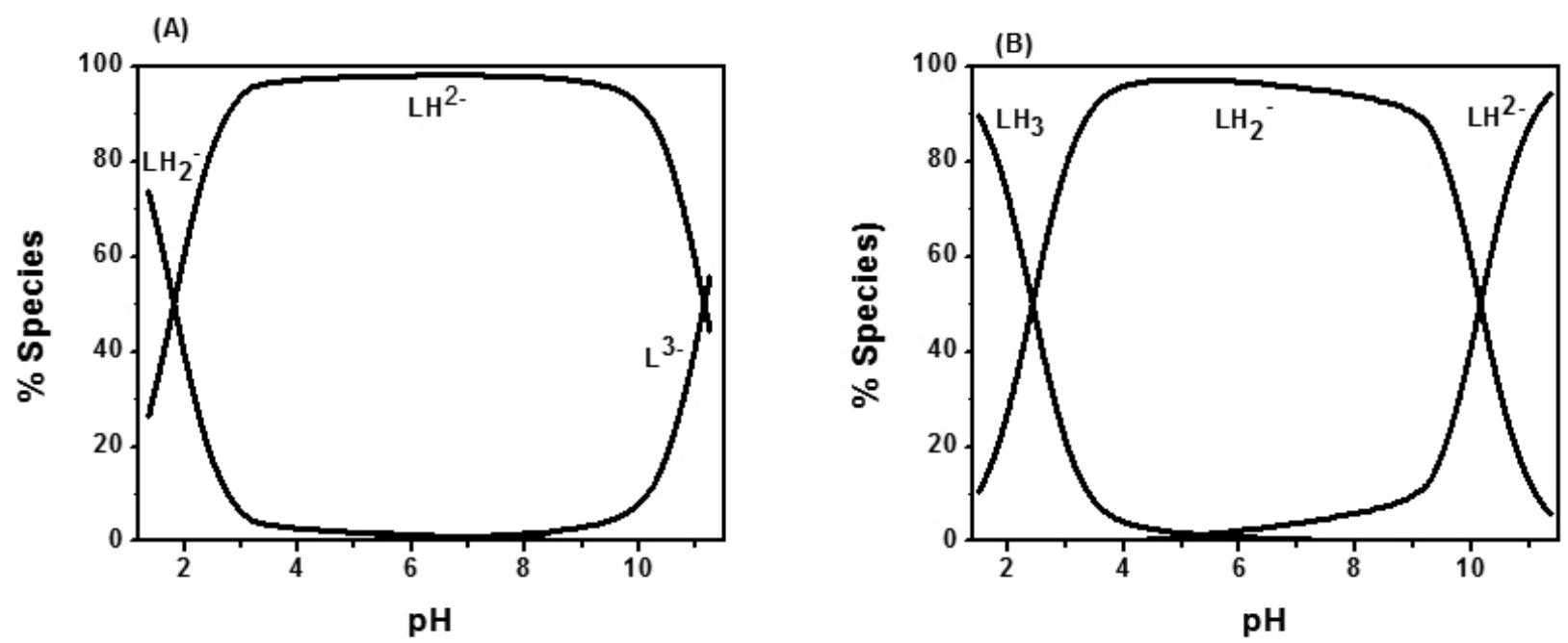

Figure 4: Species distribution diagrams of (A) 5-Sulphosalicylic acid (B) 5-Hydroxysalicylic in 1.5\% w/v CTAB-water mixture.

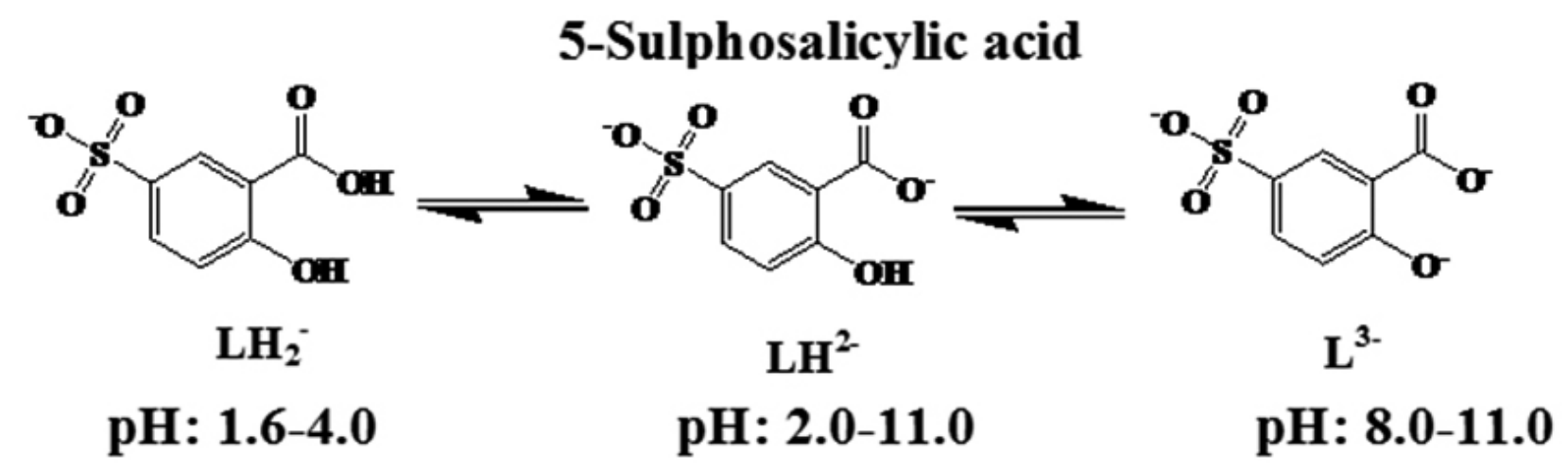

\section{5-Hydroxysalicylic acid}

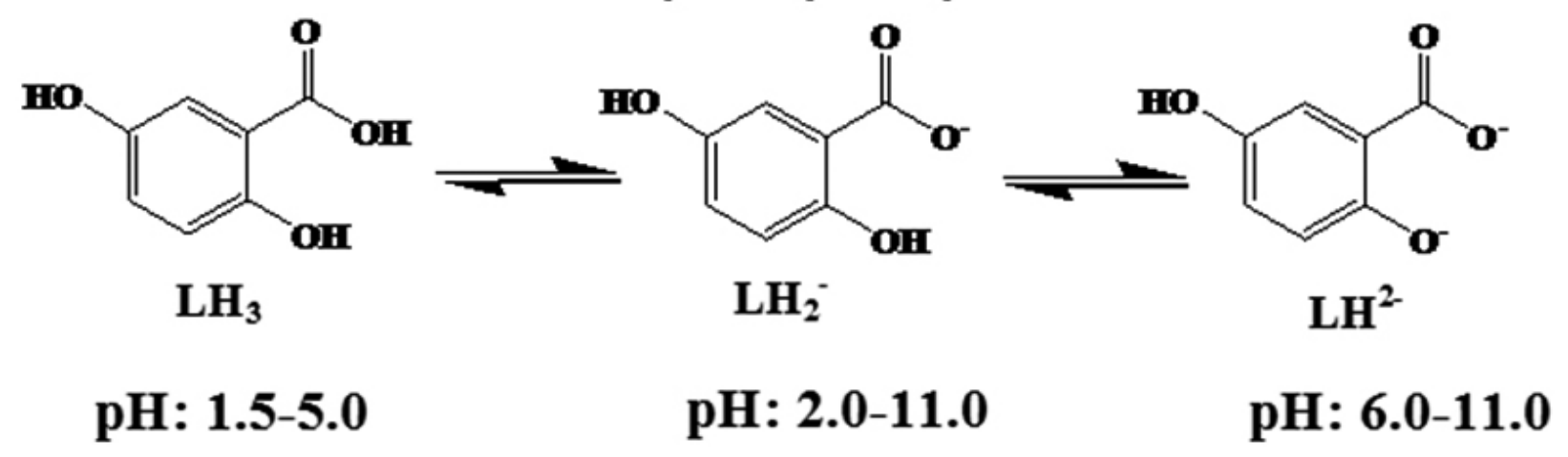

Figure 5: Protonation-deprotonation equilibria of (A) 5-Sulphosalicylic acid (B) 5-Hydroxysalicylic acid 

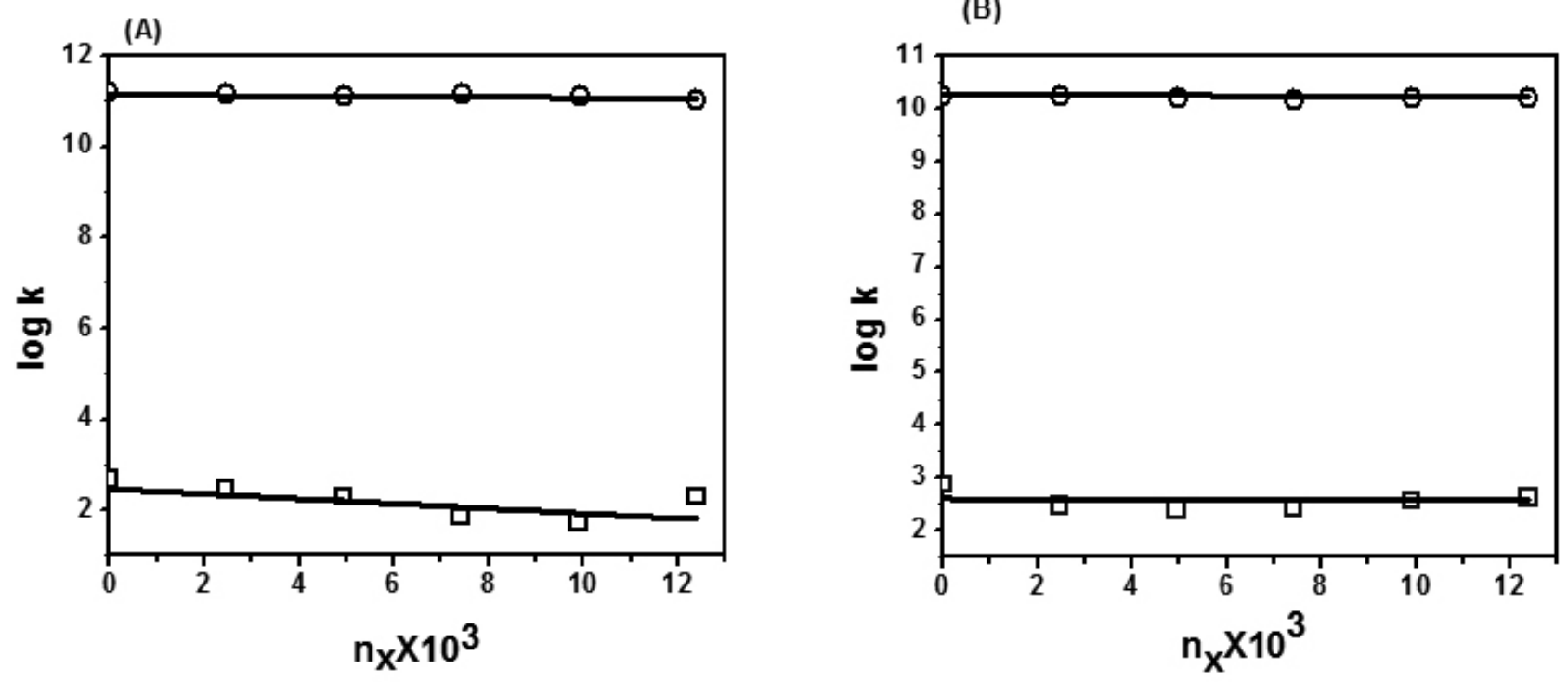

Figure 6: Variation of stepwise protonation constant $(\log K)$ with mole fraction of CTAB in CTAB-water mixtures. (A) 5-Sulphosalicylic acid (B) 5-Hydroxysalicylic acid ( $\square) \log \mathrm{K}_{1},(\circ) \log _{2}$.

\section{4. Effect of Systematic Errors in Best Fit Model}

MINIQUAD75 does not have provision to study the effect of systematic errors in the influential parameters like the concentration of ingredients and electrode calibration on the magnitude of protonation constant. In order to rely upon the best chemical model for critical evaluation and application under varied experimental conditions with different experimental with different accuracies of data acquisition, an investigation was made by introducing pessimistic errors in the concentration of alkali, mineral acids and the ligands. The results of a typical system given in Table 4 emphasize that the errors in the concentrations of alkali and mineral acid affects the protonation constants more than that of the ligand.

Table 4: Effect of errors in influential parameters on the protonation constants in $2.0 \%(\mathrm{w} / \mathrm{v}) \mathrm{CTAB}$-water mixture.

\begin{tabular}{|c|c|c|c|c|c|}
\hline \multirow{3}{*}{$\%$ Error } & \multirow{3}{*}{ Ingredient } & \multicolumn{4}{|c|}{$\log \beta_{\mathrm{mlh}}(\mathrm{SD})$} \\
\hline & & \multicolumn{2}{|c|}{ 5-Sulphosalicylic acid } & \multicolumn{2}{|c|}{ 5-Hydroxysalicylic acid } \\
\hline & & LH & $\mathrm{LH}_{2}$ & LH & $\mathrm{LH}_{2}$ \\
\hline & 0 & $11.15(2)$ & $12.96(3)$ & $10.15(4)$ & $12.57(6)$ \\
\hline \multirow[t]{4}{*}{ Acid } & +5 & $11.51(2)$ & $13.63(3)$ & $10.47(4)$ & $13.31(7)$ \\
\hline & -5 & $10.78(3)$ & $12.26(4)$ & $9.80(5)$ & $11.84(8)$ \\
\hline & +2 & $11.29(2)$ & $13.24(3)$ & $10.28(4)$ & $12.86(6)$ \\
\hline & -2 & $11.01(3)$ & $12.69(3)$ & $10.01(4)$ & $12.28(7)$ \\
\hline \multirow[t]{4}{*}{ Alkali } & +5 & $10.44(6)$ & $12.03(6)$ & $9.64(7)$ & $11.72(9)$ \\
\hline & -5 & $11.86(6)$ & $13.98(6)$ & $10.63(4)$ & $13.47(7)$ \\
\hline & +2 & $10.89(3)$ & $12.61(3)$ & $9.95(5)$ & $12.23(7)$ \\
\hline & -2 & $11.40(2)$ & $13.32(3)$ & $10.34(3)$ & $12.92(6)$ \\
\hline \multirow[t]{4}{*}{ Ligand } & +5 & $11.65(3)$ & $13.72(4)$ & $10.29(3)$ & $12.79(5)$ \\
\hline & -5 & $11.15(2)$ & $12.92(3)$ & $9.99(5)$ & $12.36(7)$ \\
\hline & +2 & $11.50(3)$ & $13.48(3)$ & $10.21(3)$ & $12.65(6)$ \\
\hline & -2 & $11.30(2)$ & $13.17(3)$ & $10.09(4)$ & $12.49(7)$ \\
\hline \multirow[t]{4}{*}{$\log F$} & +5 & $11.15(2)$ & $12.95(3)$ & $10.12(4)$ & $12.45(6)$ \\
\hline & -5 & $11.17(2)$ & $13.02(3)$ & $10.18(4)$ & $12.71(6)$ \\
\hline & +2 & $11.16(2)$ & $12.99(3)$ & $10.14(4)$ & $12.53(6)$ \\
\hline & -2 & $11.16(2)$ & $12.99(3)$ & $10.17(4)$ & $12.63(6)$ \\
\hline \multirow[t]{4}{*}{ Volume } & +5 & $11.16(2)$ & $12.98(3)$ & $10.15(4)$ & $12.58(6)$ \\
\hline & -5 & $11.16(2)$ & $12.98(3)$ & $10.15(4)$ & $12.58(6)$ \\
\hline & +2 & $11.17(2)$ & $12.93(3)$ & $10.16(4)$ & $12.56(6)$ \\
\hline & -2 & $11.15(2)$ & $13.03(3)$ & $10.15(4)$ & $12.59(6)$ \\
\hline
\end{tabular}




\section{CONCLUSIONS}

1. 5-Sulphosalicylic acid $\left(\mathrm{LH}_{3}\right)$ has two ionizable hydrogen ions, which are the protons of the carboxyl groups and hydroxyl groups. $\mathrm{K}_{1}$ and $\mathrm{K}_{2}$ are the corresponding protonation constants of the carboxylate and phenolate groups, respectively. The deprotonation of the sulfonic acid group takes place at very low $\mathrm{pH}$, which makes the use of a glass electrode unreliable in determining the corresponding protonation constant.

2. 5-Hydroxysalicylic acid has three dissociable protons and can forms $\mathrm{LH}_{3}$ at low $\mathrm{pH}$ and gets deprotonated with the formation of $\mathrm{LH}_{2}^{-}$and $\mathrm{LH}^{2-}$ with increase in $\mathrm{pH}$. The deprotonation of the second hydroxyl group takes place at very high $\mathrm{pH}$, which makes the use of a glass electrode unreliable in determining the corresponding protonation constant. $\mathrm{K}_{1}$ and $\mathrm{K}_{2}$ are the corresponding protonation constants of the carboxylate and phenolate groups, respectively.

3. Secondary formation functions-number of moles of alkali consumes per mole of the ligand and average number of moles of protons bound per mole of the ligand-are useful in detecting the number of protonation equilibria and in guessing the approximate protonation constants.

4. The linear variation of $\log$ values of protonation constants of 5-Sulphosalicylic acid and 5-Hydroxysalicylic acid with increasing mole fraction of $\mathrm{CTAB}$ in $\mathrm{CTAB}$-water mixtures indicates the dominance of electrostatic forces in the protonation-deprotonation equilibria.

5. The effect of systematic errors in the influential parameters shows that the errors in the concentrations of alkali and mineral acids will affect the protonation constants more than that of the ligand.

\section{REFERENCES}

1. E. Pelizetti, E. Pramaro, Anal. Chim. Acta. 169, 1, (1983)

2. P. Ezzio, P. Edmondo, Anal. Chim. Acta. 117, 403, (1980)
3. C. J. Drummond, F. Grieser, T. W. Healy, J. Chem. Soc., Faraday Trans.1. $85,521,(1989)$

4. G. S. Hartley, Trans Faraday Soc. 30, 444, (1934)

5. G. S. Hartley, J. W. Roe, Trans. Faraday Soc. 36, 101, (1940)

6. C. A. Bunton, Catal. Rev. Sci. Eng. 20, 1, (1979)

7. C. A. Bunton, L. S. Romsted, L. Sepulveda, J. Phys. Chem. 84, 2611, (1980)

8. H. Chaimovich, M. J. Politi, J. B. S. Bonilha, F. H. Quina, J. Phys. Chem. 83, 1951, (1979)

9. R. S. Rao, G. N. Rao, Computer Applications in Chemistry, Himalaya Publishing House, Mumbai, 2005, 302-309.

10. G. Gran, Analyst. 77, 661, (1952)

11. G. Gran, Anal. Chim. Acta. 206, 111 (1988)

12. M. Ramanaiah, B. B.V. Sailaja, Chem. Speciat. Bioavail. 26, 119, (2014)

13. M. Ramanaiah, S. Goutham sri, B. B.V. Sailaja, Bull. Chem. Soc. Ethiop, 28, 383, (2014)

14. K. V. S. Devi, B. Ramaraju, G. N Rao, Acta. Chimica. Slovenica. 57 398, (2010)

15. B. Ramaraju, K. V. S. Devi, N. Padmaja, G. N. Rao, J. Indian Chem. Soc. $56,842,(2011)$

16. M. Ramanaiah, P Seetharam, B. B.V. Sailaja, J. Indian Chem. Soc. 91 1011, (2014)

17. P. Gans, A. Sabatini and A. Vacca, Inorg. Chim. Acta. 18, 237, (1976)

18. M. Ramanaiah, CH. Nageswara Rao, B. B.V. Sailaja, Proc. National Acad. Sci. India. 84, 485, (2014)

19. H. Schneider, Top. Curr. Chem. 68, 103, (1976)

20. D. Feakins, R. D. O. Neille, W. E. Woghonie, J. Chem. Soc. Faraday Trans. 1. 79, 2289, (1983)

21. M. Born, Z. Phys. 1, 45, (1920) 